soil which overlay them. While using bronze, the people were also employing artefacts of stone and of slate. They also cultivated grain, using a species of barley. In their mode of life they were pastoral, and seem to have drawn little from the sea except shell-fish. Adjacent to the second dwelling lies a third, which in its turn had been subjected to three different occupations. The first and the second of these occurred during the final phase of the Bronze Age in Shetland, and the last after bronze had given place to iron.

This past season, while it saw, seemingly, the termination of the excavation of the prehistoric site, witnessed the opening of a fresh epoch in the exploration of a settlement of the early Norse invaders. A house has been uncovered measuring nearly
$100 \mathrm{ft}$. in length, $12 \mathrm{ft}$. in breadth at either end, and $17 \mathrm{ft} .6 \mathrm{in}$. in the centre, the walls of which in part still stand to a height of $3 \mathrm{ft}$.- - probably not much below the original elevation, as the superstructure would be of wood and turf with a roof of timber, partially supported on posts.

Numerous relics have been found, including combs and pins of bone, pins of bronze and a remarkable collection of pieces of slate bearing lines and devices in graffito. One of these, a tablet 7 in. $\times 2$ in., shows a Viking galley with high prow and stern, with mast and steering oar, and the crew indicated by strokes rising from the deck.

Evidence of other buildings of the Norse period has been discovered, and further exploration should produce interesting results.

\title{
Technical Aspects of Emulsions
}

A SYMPOSIUM on the technical aspects of emulsions, organised by the British Section of the International Society of Leather Trades' Chemists, was held on December 7 at University College, Gower Street, Prof. F. G. Donnan being in the chair, and the attendance numbering more than two hundred.

Dr. W. Clayton dealt with the subject of emulsions from the point of view of the patent literature, particular mention being made of the modern idea of 'balanced' emulsifying agents with lipophile-hydrophile groups, and several patent specifications claiming the use of a preformed emulsion as an emulsifying agent of unusual virtue. Dr. R. M. Woodman discussed the problem associated with the preparation of emulsions for horticultural spraying. The formation of opposite type emulsions with one pair of liquids and the same emulsifier, the stability to ageing and to subsequent mechanical treatment of the two types in dual systems near the common phase volume ratio, and the danger to plants arising from the use of these dual emulsion systems were some of the main points discussed.

Emulsions and emulsification in the wool textile industry were the subjects of the contribution by Dr. J. B. Speakman and Dr. N. H. Chamberlain, and it was shown that the ease of removal of thin films of oil from textile fabrics is determined by adhesion phenomena as well as by the magnitude of the oilwater interface. Dr. J. W. Corran raised some interesting points in connexion with the manufacture of mayonnaise, a typical food emulsion. Egg yolk, due to the lecithin present, is the most effective edible substance in the preparation of the emulsion, but another substance, cholesterol, antagonises this action. The superiority of fresh egg as compared with preserved yolk is due not only to hydrolytic changes in the lecithin on keeping, but also to the increased relatively unfavourable influence of the cholesterol. The mustard used in manufacture confers an added margin of stability on the product. The influence of the method of mixing, etc. was discussed at some length.

Mr. R. I. Johnson described various types of agitators, colloid mills and homogenisers used in the production of industrial emulsions. The chief factors influencing the design of homogeniser pump systems and the homogenising valve were considered and reference was made to two-stage homogenisation. Mr. R. Dorey detailed some work on the effect of the mode of preparation on the dispertion of soapstabilised emulsions, taking as examples emulsions of $(a)$ olive oil with sodium oleate and $(b)$ arachis oil and potassium oleate. The results given in the form of size frequency analyses indicate that the dispersion of this type of soap-stabilised emulsion is improved if the soap is allowed to be formed in situ during the emulsification process.

The mechanism of emulsification was dealt with by Prof. H. Freundlich. The stabilising influence of gases on emulsions produced by ultrasonic waves is most likely a secondary effect, thin layers of gas on the surface preventing or retarding the coalescence of the droplets. Ultrasonic waves acting upon an emulsion (or a coarse suspension) in a thick-walled capillary tube cause striations owing to stationary longitudinal waves in the liquid. In the nodes of these striations large drops are formed, presumably owing to an orthokinetic coagulation of the droplets when travelling from the antinodes to the nodes. It is probable that the facts which are instrumental in the formation and destruction of emulsions by ultrasonic waves are of general importance when producing emulsions by any mechanical means.

Dr. L. A. Jordan discussed the stability of emulsions in thin films with special reference to emulsion paints of the oil-in-water type. The emulsifying agent is absorbed upon the oil-water interface, and the conditions of formation of the interfacial layer determine the ageing effects produced on emulsions. One necessary condition is adsorption in one phase and solution in the other of the emulsifying agent forming the interface, while stability is dependent upon the formation of a tightly packed orientated stable monomolecular layer.

L. G. Gabriel detailed the methods of preparing asphaltic bitumen emulsions. He mentioned that it has been established that high viscosity emulsions prepared from some bitumens are due to the presence in the bitumen of finely divided water-soluble substances which serve to produce an osmotic equilibrium between the solutions, which they form inside the dispersed bitumen particles, and the bulk aqueous phase without. This work has led to a means of varying the viscosity of such emulsions without changing the bitumen content. Emulsions in the leather industry was the subject of the contribution by W. R. Atkin and F. C. Thompson. The process of fat-liquoring consists of two stages, first the absorption of oil from the dilute emulsion, and the electrical 
discharge of oil droplets, and secondly the breaking of the absorbed emulsion by acid and by basic chromium compounds in the interior of the leather.

A valuable application of emulsions to medical science was afforded by a paper by V. G. Walsh and A. C. Fraser on the use of highly dispersed emulsions in the treatment of toxæmic conditions. It dealt in the main with the practical application of the observation that if very large doses of toxin are incubated at body temperature for half an hour with olive oilsoap emulsion, they are rendered non-toxic when injected intravenously. This has been made the basis for the treatment of toxæmic conditions, and more particularly of lobar pneumonia. Other points discussed were the selective adsorption of toxin by emulsion and the administration of vaccines and certain drugs in combination with emulsion, which enabled larger doses to be given without the usual effects of overdose, etc.

H. B. Stevens and W. H. Stevens dealt with the question of rubber latex, and pointed out that much scientific investigation is still required to elucidate the facts underlying all the commonly used processes for coagulating rubber latex.

\section{University and Educational Intelligence}

Birmingham.-With the object of creating a memorial to the late Sir Bertram Windle, first professor of anatomy and first dean of the faculty of medicine in the University, Sir Charles Hyde has given $£ 5,000$ towards the cost of the new dissecting room to be built at the new medical school on the understanding that it shall be called the "Bertram Windle Dissecting Room". Sir Charles has also given $£ 300$ to found a 'Windle prize' to be competed for by students in the Department of Anatomy. In his letter to the Pro-Chancellor, Sir Charles writes : "I am glad to offer these donations as I realise that they will not only carry out the object I have in mind but will also to some extent assist in the finance of the new Medical School which is naturally causing some anxiety to the Council and to yourself."

Cambridge.-W. S. Mansfield, Emmanuel College, has been appointed director of the University Farm.

Dr. W. B. Lewis has been elected to an unofficial (Drosier) fellowship for research in physics at Gonville and Caius College.

UNEMPLOYMENT among teachers is serious throughout the United States. In a recent report by the New York City Board of Education examiners, it is stated that applicants now on the eligible list have waited so long and are presumably so rusty that new examination should be required before they are appointed. The report adds that their attitude toward education, toward society, toward life itself is unquestionably antagonistic and many have embraced a radical social and political philosophy. Among the teachers there is a prevalent opinion that the fundamental industries of providing food, clothing, warmth and shelter should be divorced from profit and be conducted solely for the general welfare, as are lighthouses, highways, parks and schools. Not only so, but their National Education Association proposes they should teach this doctrine in the schools.

\section{Science News a Century Ago}

\section{Resources and Statistics of Nations}

"Under the above title," said the Times on December 17, 1834, "the first part of a work which promises to be a very useful one has just made its appearance. It is the undertaking of John M'Gregor Esq. F.S.S. . . . This new work on statistics confines itself to facts, and presents to its readers a collection of tables of the physical aspect, area, civil and natural divisions of countries, population, produce of mines, of agriculture, of forests, etc. ; of manufactories and fisheries etc.; military and naval forces, seaports, colonies, roads, bridges, canals and, in short, of everything connected with the science of political economy, of every nation on the globe ; which tables are the result of much personal observation and of the most authentic public and private documents which are furnished by the Governments of the different countries, and by the most accurate writers by whom the science has been illustrated. . . . The work which is about to be translated into the French and German languages . . . is at once concise, perspicuous and comprehensible."

John Macgregor, the author of this work, was born in 1797 and died in 1857. He spent many years in America, in 1840 became joint-secretary of the Board of Trade in London, and in 1847 was elected M.P. for Glasgow.

\section{Dublin and Kingstown Railway}

The last railway to be brought into operation in 1834 was that from Dublin to Kingstown. The official opening took place on December 17, and on that day the Times correspondent wrote: "This day our Kingstown Railroad opened, under very favourable auspices, crowds thronged the offices at Westlandrow and every hour a full train of carriages started 'at high pressure'. Everyone engaged in the works seems in excellent spirits at the satisfactory state of the road, engines, carriages, etc. All the machinery works well as yet, except in one particular: the springs are not sufficiently elastic to prevent sudden shocks when the carriages stop. Three or four gentlemen had on one occasion to-day their heads knocked against each other and the carriage doors, and severe contusions were the consequence. A county of Kildare gentleman's head was laid open. The majority had, however, hard Irish heads and did not mind a few knocks. The directors have prepared a splendid entertainment at Kingstown for their friends and the subscribers to the undertaking. The weather is delightful for December, and a few broken heads does not throw much damp on a scene of Irish amusement where everything else goes well."

\section{Elections to the Royal Society}

At a meeting on December 18, 1834, Sir Benjamin Brodie in the chair, thirteen additional candidates were elected into the fellowship, making a total of fifty elected in the course of the year. Their names were : the Rev. John Barlow, the Rev. James William Bellamy, William Brockedon, Thomas Galloway, Dr. Bisset Hawkins, Andrew Leith Hay, Francis Kiernan, George Lowe, Richard Owen, Benjamin Phillips, Richard Saumarez, Charles John Tynte, John Gardner Wilkinson.

The list is noteworthy for the inclusion of two candidates who afterwards each achieved the 